\title{
Agricultural land use and human presence around breeding sites increase stress-hormone levels and decrease body mass in barn owl nestlings
}

\author{
Bettina Almasi $^{1} \cdot$ Paul Béziers $^{2} \cdot$ Alexandre Roulin $^{2} \cdot$ Lukas Jenni $^{1}$
}

Received: 4 July 2014 / Accepted: 8 April 2015 / Published online: 23 April 2015

(C) Springer-Verlag Berlin Heidelberg 2015

\begin{abstract}
Human activities can have a suite of positive and negative effects on animals and thus can affect various life history parameters. Human presence and agricultural practice can be perceived as stressors to which animals react with the secretion of glucocorticoids. The acute short-term secretion of glucocorticoids is considered beneficial and helps an animal to redirect energy and behaviour to cope with a critical situation. However, a longterm increase of glucocorticoids can impair e.g. growth and immune functions. We investigated how nestling barn owls (Tyto alba) are affected by the surrounding landscape and by human activities around their nest sites. We studied these effects on two response levels: (a) the physiological level of the hypothalamus-pituitary-adrenal axis, represented by baseline concentrations of corticosterone and the concentration attained by a standardized stressor;
\end{abstract}

Communicated by Hannu Pöysä.

Electronic supplementary material The online version of this article (doi:10.1007/s00442-015-3318-2) contains supplementary material, which is available to authorized users.

Bettina Almasi

bettina.almasi@vogelwarte.ch

Paul Béziers

paul.beziers@unil.ch

Alexandre Roulin

alexandre.roulin@unil.ch

Lukas Jenni

lukas.jenni@vogelwarte.ch

1 Swiss Ornithological Institute, Seerose 1, 6204 Sempach, Switzerland

2 Department of Ecology and Evolution, Biophore Building, University of Lausanne, 1015 Lausanne, Switzerland (b) fitness parameters: growth of the nestlings and breeding performance. Nestlings growing up in intensively cultivated areas showed increased baseline corticosterone levels late in the season and had an increased corticosterone release after a stressful event, while their body mass was decreased. Nestlings experiencing frequent anthropogenic disturbance had elevated baseline corticosterone levels, an increased corticosterone stress response and a lower body mass. Finally, breeding performance was better in structurally more diverse landscapes. In conclusion, anthropogenic disturbance affects offspring quality rather than quantity, whereas agricultural practices affect both life history traits.

Keywords Anthropogenic disturbance $\cdot$ Breeding success $\cdot$ Corticosterone $\cdot$ Disturbance $\cdot$ Fitness

\section{Introduction}

Human presence and land use modify environmental conditions constantly and unpredictably for most free-ranging organisms. In particular the modification of habitats by humans or the creation of new types of habitats (e.g. agricultural land, human settlements) determines the occurrence of many organisms (Konstantinov 1996; Marzluff 2001). Broadly we can divide species into three groups: those which are restricted to pristine habitats; those which tolerate or depend on human-influenced or human-made habitats, but do not live or breed in human settlements; and the synanthropic species which live close to humans or even depend largely on human settlements and buildings for reproduction.

Human activities can have a suite of positive and negative effects on animals (Johnston 2001; Müllner et al. 2004). Understanding the extent to which animals can tolerate or 
benefit from diverse human activities is an important issue in conservation biology. Effects of humans on animals may be indirect through alterations of habitats (including food availability, parasites, etc.) or direct through disturbance and destruction of individuals (e.g. hunting) or nest sites. For example, profound changes in habitat through agriculture has allowed the expansion of many species living in open land, but the recent intensification of agriculture has led to dramatic declines in many species (e.g. Donald et al. 2001). Synanthropic species directly depend on human settlements, but may suffer from continuous disturbance. Humans often affect animals unpredictably (e.g. during the harvest). Since animals rely on specific evolved cues to choose their breeding habitats, human interventions can lead to maladaptive settlement decisions with reduced reproductive performance (Hollander et al. 2011).

Human activities, whether direct or indirect, can affect one or several response levels: (a) physiological or behavioural responses (mostly short term); (b) fitness parameters (e.g. survival, productivity) and habitat use (mostly medium term); and (c) long-term consequences for populations and species. Because an effect on one response level does not necessarily result in an effect on another response level, and because many different parameters may be affected, the effects of human activities are often difficult to ascertain.

In cases in which animals do not disappear (emigration or death), the diverse direct and indirect human activities manifest themselves often in a common physiological response (Wingfield et al. 1998; Partecke et al. 2006). Hence, physiological measures could be an appropriate tool to monitor the well-being of individuals (Wikelski and Cooke 2006). The level of glucocorticoids (stress hormones) is such a physiological measure (Madliger and Love 2014), which integrates the effects of e.g. human-induced habitat deteriorations (Zhang et al. 2011; Bauer et al. 2013; Chavez-Zichinelli et al. 2013) and direct anthropogenic disturbance (Romero and Wikelski 2002; Müllner et al. 2004; Thiel et al. 2008; Strasser and Heath 2013). Commonly, two different measures of corticosterone are used: (a) baseline glucocorticoid levels, which have an important role in energy regulation and maintain homeostatic energy balance; and (b) the release of glucocorticoids to an acute standardized stressor such as handling (acute glucocorticoid response), which mediates physiological and behavioural changes in order to cope with an acute stress situation (reviewed in Sapolsky et al. 2000); this can be regarded as a measure of how animals respond to an acute stressor. Human-derived environmental alterations or direct disturbances can last for days and lead to chronic stress which can negatively affect health and fitness (Sapolsky et al. 2000). It is commonly assumed that chronic stress leads to an increase in baseline corticosterone levels (Bonier et al. 2009b). While the majority of studies support a positive relationship between baseline glucocorticoid levels and chronic stress, especially those of food stress, there is a substantial number of studies showing no change in baseline corticosterone due to chronic stress (Dickens and Romero 2013). For the effect of chronic stress on the acute glucocorticoid stress response, there is no general prediction from the literature (Dickens and Romero 2013). The lack of a uniform pattern may be due to large betweenindividual variation (Cockrem and Silverin 2002; Almasi et al. 2010; Lynn et al. 2010) and the additional interference of life history stage, age, sex and context. Hence there is a need for studies investigating which direct or indirect human activities are reflected in elevated baseline corticosterone, indicative of a disturbance of homeostasis, or an altered glucocorticoid stress response, and whether such changes translate into a reduction of fitness parameters.

Indirect effects of human activities (habitat alterations) are well known to affect habitat use, occurrence and fitness parameters (e.g. survival, productivity). Less well known are direct effects of human presence, especially in synanthropic species which are seemingly well adapted to humans. The aim of this study is to simultaneously study the effects of both direct and indirect effects of human activities on two response levels (physiology and fitness parameters) in a synanthropic bird species, the barn owl. On the European continent the barn owl is almost entirely dependent on buildings for nesting, and hunts for voles and mice in open landscapes, mostly human-made agricultural areas where availability and accessibility of small rodents depend mainly on crop types, vegetation height, and agricultural intensity (Arlettaz et al. 2010). Hence, barn owl nestlings are potentially affected by both direct (humanmade noise and disturbance at the breeding site) and indirect (the type of agriculture determining the availability of food) human activities.

We therefore investigated how nestling barn owls are affected by the surrounding landscape and agricultural intensity (agricultural area around breeding sites, crop type, rural settlements, hedges, etc.) as well as by human activities around the nest site located in buildings (human presence and noise around breeding sites). We studied these effects on two response levels: (a) the physiological level of the hypothalamus-pituitary-adrenal (HPA) axis, represented by baseline concentrations of corticosterone and the concentration attained by a standardized stressor (hereafter referred to as the 'acute corticosterone response'); (b) fitness parameters: growth of the nestlings, which in many species is a good predictor of survival in the nest and after fledging (Roulin 2002), and breeding performance, i.e. number of eggs and fledglings. 


\section{Materials and methods}

\section{Study species and study area}

Barn owls breed between February and August. Females lay between two and 11 eggs per clutch and start incubation for 32 days after the first egg is laid. Females lay eggs at intervals of 2-3 days, which leads to a pronounced within-brood age hierarchy. Nestlings fledge at the age of 50-60 days (Mebs and Scherzinger 2000). The study was carried out in 2004-2006, 2009, and 2010 in an open rural landscape dominated by intensive agriculture in western Switzerland $\left(46^{\circ} 49^{\prime} \mathrm{N}, 06^{\circ} 56^{\prime} \mathrm{E}\right)$. All breeding males $(n=89)$ and females $(n=99)$ were captured during the nestling period and classified as 'yearling' or 'adult'. If adults had not been ringed as nestlings, we classified them as yearling if all primary and secondary feathers belonged to the same generation, and as adult otherwise (Taylor 1993). Females were distinguished from males by the presence of a brood patch.

In 4 of the 5 years we carried out cross-fostering experiments by swapping eggs or hatchlings between pairs of randomly chosen nests (no cross-fostering was carried out in 2005). This design was useful to partition phenotypic variation into genetic and environmental components. These experiments have already been the topic of several publications where we explain the method in detail (e.g. Roulin et al. 2010). Two hundred and sixteen nestlings for which we measured body mass were raised in a different nest (nest of rearing; $n=77$ nests) to the one where they hatched (nest of origin; $n=80$ nests), whereas 370 nestlings were raised in the same nest in which they hatched.

\section{Potential disturbance parameters and landscape characteristics}

Data on potential disturbance parameters were collected for 190 nest boxes mounted on farms in an area of $560 \mathrm{~km}^{2}$ during the breeding season in 2009. For each nest box we measured the following two disturbance parameters, which we consider as potential sources of stress for barn owls: distance $(\mathrm{m})$ to the next inhabited house, and whether there were livestock present during the breeding season within a radius of $20 \mathrm{~m}$ around the barn where the nest box was located. Both potential disturbance parameters (livestock present around barns with nest boxes and distance to the next inhabited house) stand for a more frequent and longer presence of farmers at the breeding site. We verified with the farmers whether the use of the barns had changed considerably during the last 6 years and, if necessary, adjusted the measurements.

The environment surrounding the 190 nest boxes was described with the help of geographic information system software and aerial orthophotographs (0.5-m resolution; Geodata Swisstopo-DV084371, 2004). The landscape within a radius of $1 \mathrm{~km}$ around the nest box [which corresponds to the mean home range used by breeding barn owls (Arlettaz et al. 2010)] was described with nine habitat variables: areas of wood, village, hedgerow and trees, river, orchard, vineyard, open water, swamp and agricultural land. In summer 2009, the agriculture land of the region was further subdivided into cereals (wheat, barley, rye, triticale, oats), sugar beet, meadow, maize, tobacco, sunflower, potato, colza, pea, wildflower fields and market gardening by field surveys. In the study area, meadows include fertilised grasslands that are part of the crop rotation or pastures. To estimate the degree of parcelling of the landscape, the total perimeter of the fields in a radius of $1 \mathrm{~km}$ around each nest box was calculated, so that the higher the total perimeter of the fields was, the smaller the fields were. For further details on the assessments of the landscape characteristics see Frey et al. (2011).

For the statistical analyses we considered the area of the four main landscape variables (wood, agricultural land, urban area, hedgerow and trees), of the four main crop types (cereals, sugar beet, maize, meadow) and the total perimeter of all categories, but omitted the habitat variables with areas below $5 \%$ of the total area. These variables together give a set of nine landscape characteristics. To obtain a reduced set of landscape characteristics out of the nine variables, we performed a principal components (PC) analysis and selected the components with eigenvalues larger than one (Table 1). The PCs were calculated with the library psych (Revelle 2012)

Table 1 Principal components $(P C \mathrm{~s})$ analysis of eight habitat variables and the parcelling of the landscape (sum of the perimeters of all the fields measured in a radius of $1 \mathrm{~km}$ around each barn owl nest box)

\begin{tabular}{lccc}
\hline Habitat variables & PC1 & PC2 & PC3 \\
\hline Parcelling of the landscape & & 0.46 & 0.76 \\
Hedgerow area & & 0.61 & 0.23 \\
Village area & -0.75 & -0.56 & \\
Wood area & 0.93 & & 0.15 \\
Agriculture land area & 0.81 & & -0.31 \\
Sugar beet area & 0.65 & & \\
Maize area & -0.13 & -0.13 & 0.89 \\
Meadow area & 0.84 & -0.15 & -0.15 \\
Cereal area & 3.3 & 1.7 & 1.6 \\
Eigenvalue & 0.36 & 0.55 & 0.73 \\
Cumulative variance & & & \\
\hline
\end{tabular}

The correlations between the original variables and the first three PCs (eigenvalues $>1$ ) are given. The factor scores of the first three PCs (PC1-3) were used in the mixed-effect model analyses. Values in italic represent parameters with a high factor score 
and we rotated the axis with the varimax function from the library GPArotation (Bernaards and Jennrich 2012). To link the landscape characteristics in 2009 to measurements of nestling corticosterone levels, body mass and breeding performance over the last 6 years, we assumed that the habitat did not change considerably during this period. Farms are usually small in the study area (26.6 ha) and they follow a crop rotation which lasts usually for 6 years. This means that locally there can be differences between years but on the level of the farm the agricultural land use should be quite stable (Bundesamt für Landwirtschaft 2014). This assumption is supported by the observation that the proportion of a given prey species in a given nest site was significantly repeatable over the years in the study area (Roulin 2004a). Over a longer period of time there is a small trend that crop area decreased and intensive meadows increased (Bundesamt für Landwirtschaft 2014).

\section{Assessment of baseline and stress-induced corticosterone levels}

We collected several blood samples of barn owl nestlings of various ages [range 4-60 days, mean $32 \pm 0.4$ (SE) days] to measure baseline corticosterone and the acute corticosterone response to handling for other studies. Baseline samples were taken within 3 min after opening the nest box as the increase in corticosterone during the first $3 \mathrm{~min}$ of the onset of the stress situation is marginal (Romero and Reed 2005; Roulin et al. 2010). After taking the baseline sample birds were weighed (range 30-460 g, mean $304 \pm 3 \mathrm{~g}$ ) and then kept in cloth bags until a second blood sample was taken 25 min after capture to measure the acute corticosterone response to handling. In the barn owl the 25-min blood sample captures the peak of the corticosterone response to an acute stress situation (mean baseline corticosterone, $8 \pm 1.1 \mathrm{ng} / \mathrm{ml} ; 10 \mathrm{~min}$ after capture, $24 \pm 1.8 \mathrm{ng} / \mathrm{ml}$; $25 \mathrm{~min}$ after capture, $37 \pm 1.7 \mathrm{ng} / \mathrm{ml} ; 40 \mathrm{~min}$ after capture, $33 \pm 3.6 \mathrm{ng} 7 \mathrm{ml}$; own unpublished data).

\section{Total corticosterone assay}

Plasma total corticosterone concentration was determined by using an enzyme immunoassay (Munro and Stabenfeldt 1984; Munro and Lasley 1988) following Müller et al. (2006). Ten microlitres of plasma was added to $190 \mu \mathrm{l}$ water, and from this solution we extracted corticosterone with $4 \mathrm{ml}$ dichloromethane, which was re-dissolved in phosphate buffer and measured in triplicate in the enzyme immunoassay. The dilution of the corticosterone antibody (Chemicon; cross-reactivity-11-dehydrocorticosterone $0.35 \%$, progesterone $0.004 \%$, 18-hydroxy-11-deoxycorticosterone $0.01 \%$, cortisol $0.12 \%$, and aldosterone
$0.06 \%)$ was $1: 8000$. We used horseradish peroxidase (1:400 000) linked to corticosterone as the enzyme label and 2,2'-azino-bis(3-ethylbenzthiazoline-6-sulphonic acid as substrate. The concentration of corticosterone in plasma samples was calculated by using a standard curve run in duplicate on each plate. If the corticosterone concentration was below the detection threshold of $1 \mathrm{ng} / \mathrm{ml}$ the analysis was repeated with 15 or $20 \mu \mathrm{l}$ plasma. Plasma pools from chicken with a low and high corticosterone concentration were included as internal controls on each plate. Intraassay variation ranges from 5 to $17 \%$ and inter-assay variation from 12 to $25 \%$, depending on the concentration of the internal control.

\section{Statistical analyses}

We modelled the effects of different landscape characteristics and two potential disturbance parameters on baseline corticosterone, the acute corticosterone response, and body mass of nestling barn owls, and on breeding performance of adult barn owls, with linear mixed-effect models. We used model selection and model averaging based on Akaike's information criterion corrected for small sample size (AICc) (Burnham and Anderson 2002). For all analyses we used the statistical software R version 2.15.1 (R Development Core Team 2012) and the package lme4 (Bates et al. 2012). To directly compare effect sizes of fixed effects on different measurement scales and to allow comparison of main effects when interactions were present, we standardized numeric input variables to means of zero and SDs of one.

To model the effects of landscape characteristics and potential disturbance parameters on the two corticosterone measurements and nestling body mass we created three different sets of mixed-effects models. To account for different origins of the nestlings we always included the nest of origin and nest of rearing as two random intercepts. Nestling identity was introduced as an additional random intercept to account for repeated measurements of individuals. Our full models for the model sets with baseline corticosterone and the acute corticosterone response as dependent variables contained nestling age in days, relative body mass [residuals of mass $(\mathrm{g})$ in relation to age and age ${ }^{2}$ ], Julian date (hereafter 'date'), and brood size (number of nestlings in the nest box on the day of sampling), the three PCs of landscape characteristics (PC1, PC2, PC3; Table 1) and the two potential disturbance variables (distance of the nest box to the next inhabited house, and whether livestock were present within $20 \mathrm{~m}$ of the nest box). The first PC represents the total agricultural area as well as the different crop type areas. Since vegetation height of these areas varies strongly over the course of the season we also included the interaction date $\times \mathrm{PC} 1$. The full model with nestling body 
mass as dependent variable contained the above-mentioned variables except relative body mass and additionally age ${ }^{2}$ and age ${ }^{3}$ and time (time of day when we collected the blood sample). For the three dependent variables we constructed three sets of models with all possible combinations of the landscape (PC1, PC2, PC3) and disturbance (distance to inhabited house, and livestock present) variables and calculated AICc for all models. To account for model selection uncertainty and to assess the importance of the PCs and the potential disturbance variables we used model averaging (Burnham and Anderson 2002) of all models with a difference in AICc $<4$ from the model with the lowest AICc (hereafter called 'top models'). The functions available in the $\mathrm{R}$ package MuMln were used. We calculated Akaike model weights (Anderson et al. 2000) of the top models, which indicate the probability that a given model is the best among the whole set of candidate models. Weights of models sum up to 1 by definition. Parameter estimates are multiplied by the weight of the particular model and summed over all top models to give the weighted average of the estimated parameters. We always present averaged standardised effect sizes, averaged SEs and averaged $95 \%$ confidence intervals (CI) using the function model.avg and confint from the package MuMln. Averaged effect sizes are significantly different from zero if their $95 \%$ CI do not include zero.

Note that the predictor variables of interest (distance to inhabited house, PC1, PC2, PC3, and livestock present around breeding sites) were not correlated among each other. There was a weak correlation between PC1 and date $(r=0.21)$, and between brood size and distance to inhabited house $(r=-0.25)$, which did not cause any numeric problems in the models. All other predictor variables of interest were not correlated with the other covariables.

To visualize the effect sizes we used Bayesian methods. For the top models we simulated a random sample ( $n$ total $=2000, n$ for each model $=n \times$ model weight) from the joint posterior distribution of the model parameters using the function sim of the package arm. For each of the 2000 sets of simulated model parameters, we obtained predicted values for all new values of the predictor variables. The new values of the predictor variables always span the whole range of the variable (or each factor level) of interest; all other variables were held constant at their mean. In this way, we obtained for each new value of the variable of interest a sample of 2000 random draws from the posterior distribution of the model predictions. From this sample, we used the mean as predicted value and the 2.5 and $97.5 \%$ quantiles as lower and upper limits of the $95 \%$ credible interval (CrI).

To model the effects of landscape characteristics and potential disturbance parameters on breeding performance of the adult barn owls we used clutch size and number of fledglings as proxies for breeding performance and created two sets of mixed-effects models which always contained mother identity, father identity and brood identity as random effects. Our full models for the model sets with clutch size and number of fledglings as dependent variables contained mother and father age category (yearling or adult), relative nestling body mass [residuals of mass $(\mathrm{g})$ in relation to age and age ${ }^{2}$, date, the three PCs of landscape characteristics (PC1, PC2, PC3; Table 1) and the two potential disturbance variables (distance to the next inhabited house, and whether livestock were present). We then built the model sets, model averaging and predictions as described above.

Assumptions of normality for linear mixed-effect models were verified for each of the full models per set by visual inspection of the residuals.

\section{Results}

\section{Baseline corticosterone}

The model selection procedure for baseline corticosterone yielded eight models with similar AICc values $(\delta \mathrm{AICc}<4$; ESM Table S1A). Among the three landscape parameters (PC1-3), PC3 was the variable with the largest averaged effect size whose $95 \%$ CI did not contain zero (Tables 2, S1) and was present in all eight top models. A high factor score of PC3 represents a landscape with many small field parcels and many meadows and was weakly positively correlated with baseline corticosterone (Fig. 1c). The second most important landscape variable based on averaged effect size obtained from the model selection procedure was the interaction of $\mathrm{PC} 1$ with date and was present in six out of the eight top models (Tables 2, S1). A high factor score of PC1 represents intensive agricultural land use [PC1 was positively related with agricultural area and the area of the three main crop types (cereal, sugar beet and maize) and negatively with wood area; Table 1]. Early during the breeding season baseline corticosterone was weakly negatively correlated with the intensity of agricultural land use, while late in the season baseline corticosterone concentration was higher in more intensively cultivated areas (Fig. 1a). The potential disturbance variable livestock present had the largest averaged effect size and was present in six of the eight top models (Tables 2, S1). Nestlings had lower baseline corticosterone levels when growing up at sites where livestock were present (Table 2; Fig. 2). The large and overlapping $95 \% \mathrm{CrI}$ in the effect size plot (Fig. 2a) shows that there is a significant difference between nestlings in sites with or without livestock but the mean corticosterone concentration can only be estimated with a large uncertainty. The second PC and the distance to 
Table 2 Model-averaged standardised estimates, unconditional SE, and $95 \%$ confidence intervals $(C I)$ for three models with the dependent variables baseline corticosterone, the acute corticosterone response, and nestling body mass of nestling barn owls

\begin{tabular}{|c|c|c|c|c|c|c|c|c|c|}
\hline \multirow[t]{2}{*}{ Explanatory variables } & \multicolumn{3}{|c|}{ Log (baseline corticosterone) ${ }^{\mathrm{a}, \mathrm{b}}$} & \multicolumn{3}{|c|}{ Acute corticosterone response ${ }^{c}$} & \multicolumn{3}{|c|}{ Nestling body mass ${ }^{\mathrm{d}}$} \\
\hline & Estimate & SE & $95 \% \mathrm{CI}$ & Estimate & SE & $95 \% \mathrm{CI}$ & Estimate & SE & $95 \% \mathrm{CI}$ \\
\hline$i$ & 203.3 & 0.2 & $(169.7,237.1)$ & 44.1 & 7.4 & $(29.6,58.5)$ & 356.8 & 61.8 & $(345.4,368.1)$ \\
\hline$a$ & 0.1 & 2.0 & $(-4.03,4.3)$ & 10.0 & 1.2 & $(7.5,12.6)$ & 48.9 & 1.9 & $(45.1,52.7)$ \\
\hline$a^{2}$ & - & & & - & & & -29.2 & 0.8 & $(-30.8,-27.6)$ \\
\hline$a^{3}$ & - & & & - & & & 1.9 & 0.6 & $(0.7,3.1)$ \\
\hline$m$ & -2.0 & 0.1 & $(-0.33,-0.1)$ & -0.1 & 0.02 & $(-0.16,-0.07)$ & - & & \\
\hline$b$ & 2.0 & 2.0 & $(-2.80,6.9)$ & -2.0 & 1.4 & $(-4.7,0.8)$ & -0.1 & 1.6 & $(-3.3,3.1)$ \\
\hline$t$ & & & & & & & -3.8 & 1.1 & $(-5.8,-1.7)$ \\
\hline$d$ & -1.0 & 2.0 & $(-6.3,3.2)$ & 1.2 & 1.3 & $(-1.3,3.7)$ & -5.4 & 1.6 & $(-8.5,-2.3)$ \\
\hline dh & 4.2 & 2.6 & $(-0.8,9.2)$ & -2.1 & 1.2 & $(-4.5,-0.3)$ & 2.01 & 2.0 & $(-1.0,5.1)$ \\
\hline ah & -11.08 & 5.1 & $(-21.0,-1.2)$ & 1.1 & 2.7 & $(-4.5,5.9)$ & -10.4 & 3.3 & $(-16.9,-3.9)$ \\
\hline PC1 & 2.20 & 2.5 & $(-2.7,7.2)$ & 2.8 & 1.3 & $(0.5,5.5)$ & -3.8 & 1.6 & $(-7.0,-0.6)$ \\
\hline PC2 & -1.52 & 2.4 & $(-6.2,3.1)$ & 1.8 & 1.3 & $(-0.7,4.3)$ & 0.2 & 0.6 & $(-2.9,3.2)$ \\
\hline PC3 & 6.6 & 2.1 & $(1.5,11.7)$ & 0.7 & 1.4 & $(-2.1,3.5)$ & -1.3 & 1.7 & $(-4.7,2.0)$ \\
\hline $\mathrm{PC} 1 \times d$ & 5.7 & 2.2 & $(1.3,10.0)$ & 0.3 & 1.2 & $(-2.1,2.8)$ & 1.5 & 1.4 & $(-1.2,4.3)$ \\
\hline
\end{tabular}

Year, brood identity and nestling identity nested in brood identity were introduced as random factors. The full models contained: intercept $(i)$; age of the nestling ( $a ; a^{2}$, and $a^{3}$ for the model with nestling body mass); Julian date $(d)$; brood size $(b)$; time of day for the model with nestling body mass as dependent $(t)$; relative body mass $(m$; for the corticosterone analysis only); livestock present within a radius of $20 \mathrm{~m}$ around the nest box (yes/no) ( $a h)$; distance to the nearest inhabited house ( $d h)$; PCs of Table $1(P C 1-3)$; and the interaction of PC1 $\times d$

Values in italic represent significant parameters

${ }^{\text {a }}$ Log (baseline corticosterone) $\times 100$

b The analyses are based on 1018 measurements of 519 individuals from 141 broods

c The analyses are based on 647 measurements of 405 individuals from 111 broods

d The analyses are based on 1116 measurements of 533 individuals from 141 broods

the next inhabited house were not good predictors for baseline corticosterone (all $95 \% \mathrm{CI}$ of the averaged effect sizes included zero; Table 1; Figs. 2b, 3a).

\section{Acute corticosterone response}

The model selection procedure for the acute corticosterone response yielded 22 models with similar AICc values $(\delta \mathrm{AICc}<4$; ESM Table S1B). The most important variable of the habitat characteristics and potential disturbance parameters was the first PC which was present in 19 of the 22 top models and had the largest averaged effect size whose $95 \%$ CI did not contain zero. The models showed that stress-induced corticosterone was higher in more intensively cultivated areas throughout the season compared to less intensively cultivated areas (Fig. 1d). The variable with the second largest effect size was distance to the nearest inhabited house, which was present in 14 of the 22 top models and its $95 \%$ CI did not include zero. The model predictions showed that stress-induced corticosterone concentrations were higher when the nest was closer to an inhabited house (Fig. 2b). The second and third PCs of landscape characteristics, the interaction of the first PC with date and the potential disturbance parameter livestock present were not good predictors for stress-induced corticosterone (all $95 \%$ CI of the averaged effect sizes included zero; Table 2).

\section{Nestling body mass}

The model selection procedure for nestling body mass yielded 15 models with similar AICc values $(\delta \mathrm{AICc}<4$; ESM Table S1C). The potential disturbance parameter livestock present was present in all top models and had the largest averaged effect size whose $95 \%$ CI did not include zero (Table 1). Body mass was lower when nestlings grew up in sites where livestock were present compared to sites without livestock (Fig. 2c). The second important variable was the first PC of landscape characteristics, which was present in 14 of the 15 best models and whose $95 \%$ CI did not include zero. Nestling body mass was lower in more intensively cultivated areas compared to less intensively cultivated areas (Fig. 1g). The second and third PCs, the interaction of date with the first PC and the distance to 

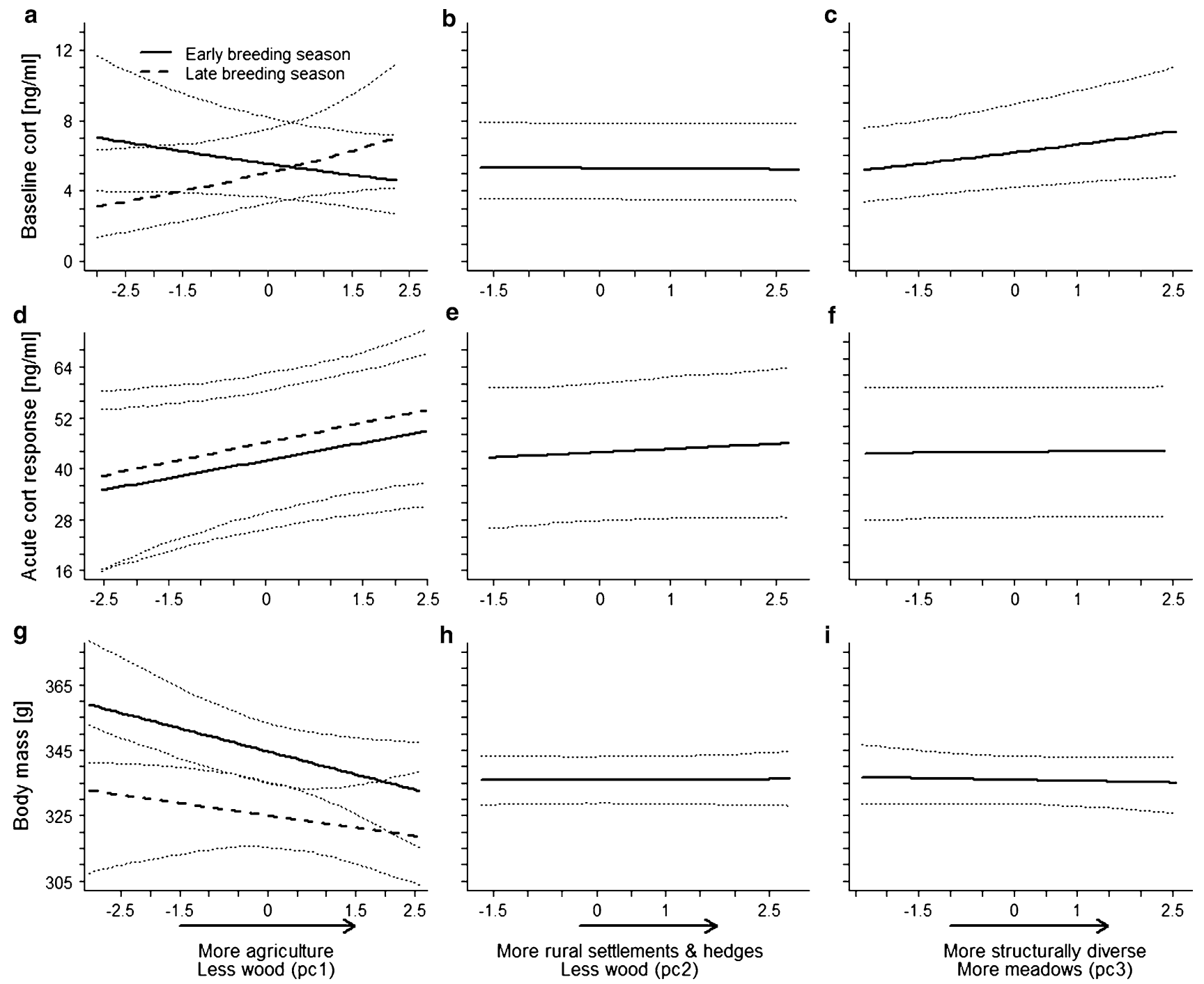

Fig. 1 a-c Predicted baseline corticosterone levels [with $95 \%$ credible intervals (CrI); dotted lines] of barn owl nestlings in relation to landscape characteristics in a radius of $1 \mathrm{~km}$ around the nest box, based on model averaging of Table $\mathrm{S} 1$ with $\mathbf{a}$ the first, and $\mathbf{b}$ the second, and $\mathbf{c}$ the third principle component $(P C)$ (see Table 1). d-f Similar graphs of the predicted acute corticosterone response (with $95 \% \mathrm{CrI}$ ) in relation to the three PCs. $\mathbf{g}-\mathbf{i}$ Similar graphs of predicted

the nearest inhabited house were not good predictors for nestling weight (all $95 \%$ CI of the averaged effect sizes included zero; Table 2).

\section{Clutch size and number of fledglings}

The model selection procedure for clutch size yielded 16 models with similar AICc values $(\delta \mathrm{AICc}<4$; ESM Table $\mathrm{S} 2 \mathrm{~A})$. The $95 \% \mathrm{CI}$ of the interaction of $\mathrm{PC} 1$ with date, which was present in five of the 16 best models, did not include zero. Clutch size increased along the season and was larger in more intensively cultivated areas late in the nestling body mass (with $95 \% \mathrm{CrI}$ ) in relation to the three PCs based on model averaging of the models given in Table S1. To illustrate the interaction of PC1 with date in graphs a and $\mathbf{g}$ (see Table 2), we arbitrarily selected an early date (solid line $25 \%$ quantile of the date, 5 May) and a late date (broken line $75 \%$ quantile of the date, 8 September)

season than in less intensively cultivated areas (Fig. 3). The second and third PCs of landscape characteristics, whether livestock were present, and the distance to the nearest inhabited house were not good predictors for clutch size (its $95 \% \mathrm{CI}$ of the averaged effect sizes included zero; Table 3).

The model selection procedure for number of fledglings yielded 13 models with similar AICc values $(\delta \mathrm{AICc}<4$; ESM Table S2B). Eleven of the 13 best models contained the second PC of landscape characteristics which was also the only parameter of interest whose $95 \% \mathrm{CI}$ did not include zero. Number of fledglings was higher in areas 

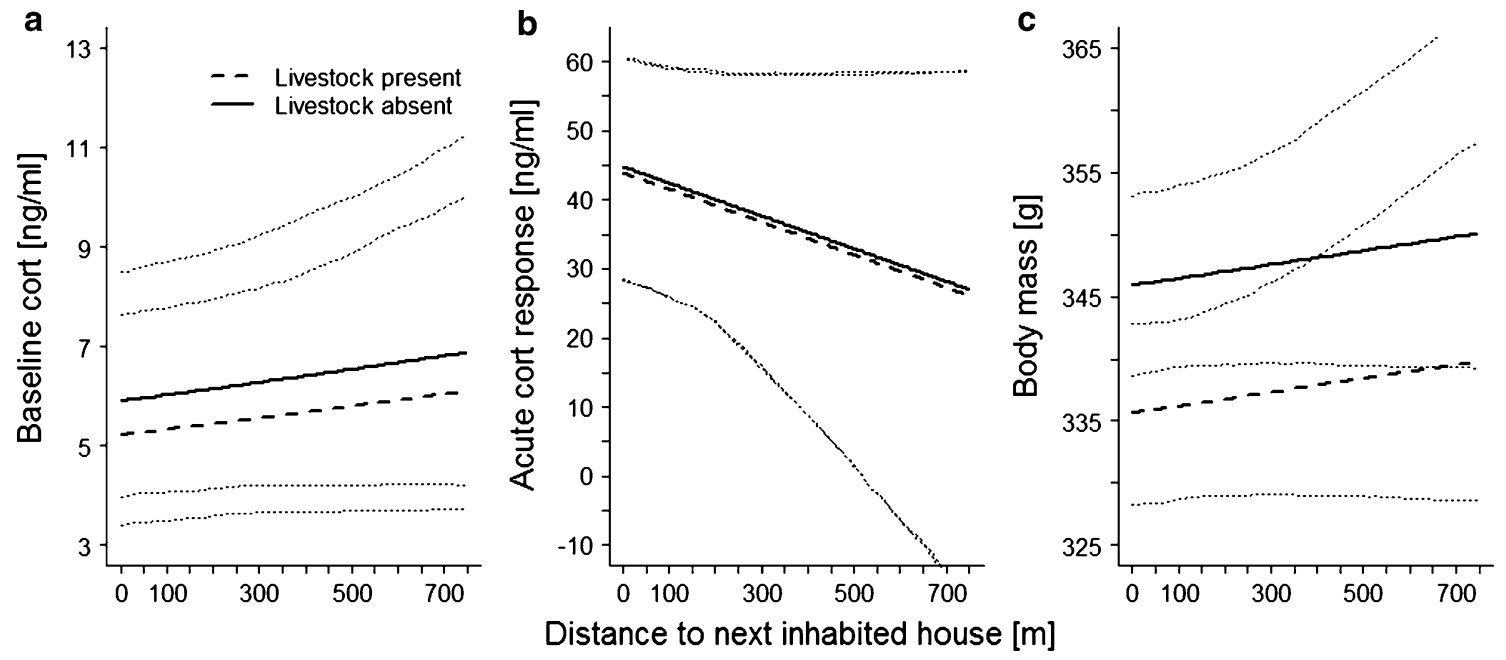

Fig. 2 a Predicted baseline corticosterone level (with $95 \% \mathrm{CrI}$ ), b predicted acute corticosterone response (with $95 \% \mathrm{CrI}$ ), and c pre-

the distance of the nest box to the next inhabited house and whether dicted body mass (with $95 \% \mathrm{CrI}$ ) of barn owl nestlings in relation to livestock were present in a radius of $20 \mathrm{~m}$ around the nest box, based on model averaging of the models given in Table S1
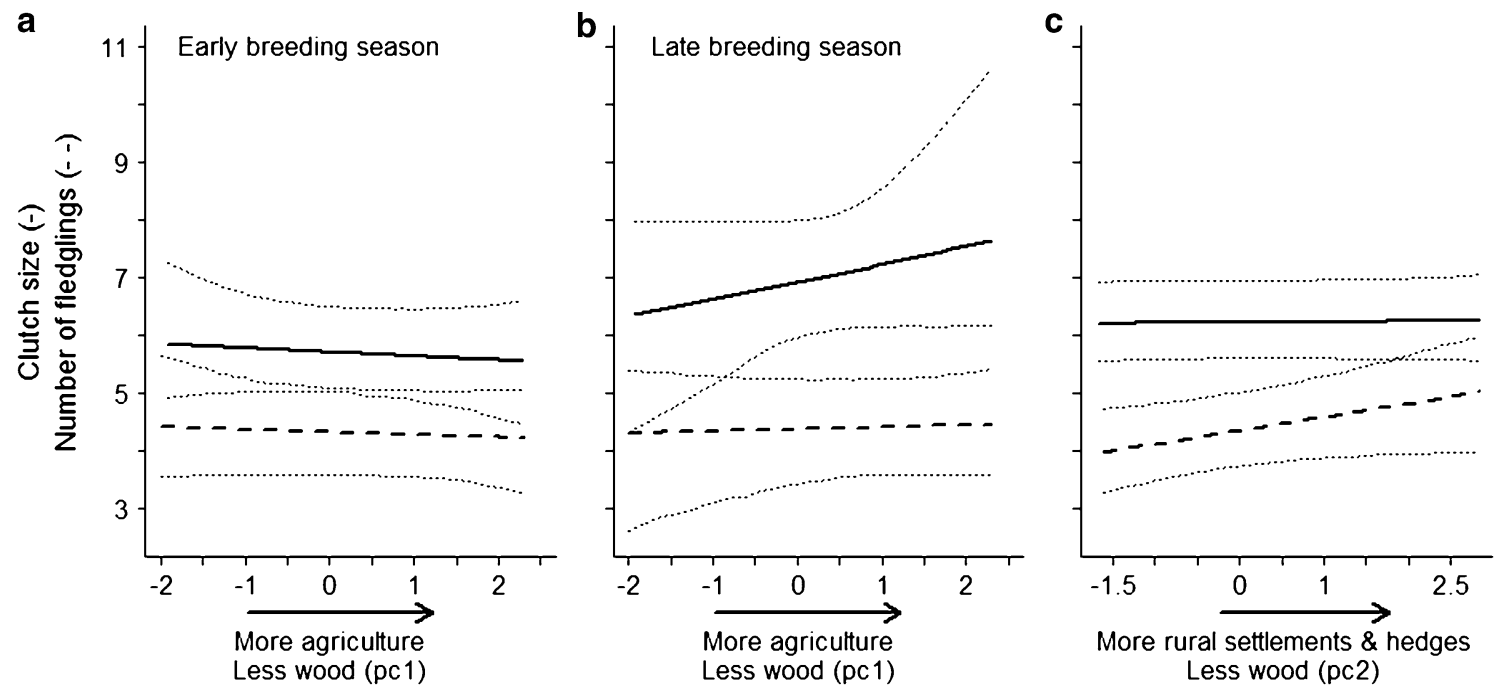

Fig. 3 Predicted clutch size (solid line) and number of fledglings (dotted line) (with $95 \% \mathrm{CrI}$ ) in the barn owl a early in the season ( $25 \%$ quantile of the date, 5 May) in relation to $\mathrm{PC} 1$; $\mathbf{b}$ late in the

with more small rural settlements and hedges and less wooded areas (Fig. 3c). The difference between clutch size and number of fledglings was smaller in areas with more small rural settlements and hedges and less wooded areas, indicating that the rearing success in these areas was higher (Fig. 3c).

\section{Discussion}

We investigated how man-made habitat characteristics and anthropogenic disturbance are related to glucocorticoid season (75\% quantile of the date, 8 September) in relation to $\mathrm{PC} 1$; and $\mathbf{c}$ in relation to PC2, based on model averaging of the models given in Table S2. For abbreviations, see Fig. 1

levels and body mass of nestling barn owls and parental breeding performance. We found that both the intensity of agriculture and indices of anthropogenic disturbance had an effect on baseline corticosterone and the acute corticosterone response and resulted in a lower nestling body mass (Table 4), which suggest that overall agricultural intensity negatively affects nestling fitness. Further, in areas with more small rural settlements and hedges more nestlings survived until fledging. This finding probably reflects that food abundance is generally higher and more stable in areas with more small rural settlements and hedges than in agricultural areas (Table 4). 
Table 3 Model-averaged standardised estimates, unconditional SE, and $95 \%$ CIs for two mixed-model analyses with the dependent variables clutch size, and number of fledglings in the barn owl

\begin{tabular}{|c|c|c|c|c|c|c|}
\hline \multirow[t]{2}{*}{ Explanatory variables } & \multicolumn{3}{|c|}{ Clutch size } & \multicolumn{3}{|c|}{ Number of fledglings } \\
\hline & Estimate & SE & $95 \% \mathrm{CI}$ & Estimate & SE & $95 \% \mathrm{CI}$ \\
\hline$i$ & 1.73 & 0.07 & $(1.63,1.84)$ & 3.68 & 0.44 & $(2.83,4.54)$ \\
\hline fa & -0.02 & 0.07 & $(-0.11,0.08)$ & 0.60 & 0.36 & $(-0.11,1.32)$ \\
\hline $\mathrm{ma}$ & 0.10 & 0.05 & $(0.03,0.18)$ & 0.01 & 0.29 & $(-0.57,0.61)$ \\
\hline$d$ & 0.05 & 0.02 & $(0.01,0.09)$ & 0.03 & 0.13 & $(-0.23,0.29)$ \\
\hline dh & 0.02 & 0.02 & $(-0.02,0.05)$ & -0.13 & 0.12 & $(-0.38,0.11)$ \\
\hline ah & 0.01 & 0.05 & $(-0.06,0.07)$ & 0.17 & 0.25 & $(-0.33,0.66)$ \\
\hline $\mathrm{PC} 1$ & 0.02 & 0.02 & $(-0.01,0.06)$ & -0.03 & 0.13 & $(-0.28,0.21)$ \\
\hline PC2 & 0.01 & 0.02 & $(-0.02,0.04)$ & 0.27 & 0.12 & $(0.03,0.51)$ \\
\hline PC3 & -0.01 & 0.02 & $(-0.04,0.03)$ & -0.03 & 0.13 & $(-0.28,0.21)$ \\
\hline $\mathrm{PC} 1 \times d$ & 0.04 & 0.02 & $(0.01,0.07)$ & 0.18 & 0.12 & $(-0.05,0.42)$ \\
\hline
\end{tabular}

Year, and female identity were introduced as random factors. The analyses are based on 126 broods of 89 breeding females. The full model contained: $i$, age of the biological mother $(m a)$, age of the biological father $(f a)$, $a h$ (yes/no), $d, d h, P C l-3$ PCs of Table 1 , and the interaction of $\mathrm{PC} 1 \times d$. For other abbreviations, see Table 2

Table 4 Summary of the effects of landscape characteristics and anthropogenic disturbance around the nest box on physiological and fitness parameters of barn owls

Baseline corticosterone Acute corticosterone Nestling body mass Clutch size Number of fledglings
response

\begin{tabular}{|c|c|c|c|c|c|}
\hline \multicolumn{6}{|l|}{ Landscape characteristics } \\
\hline $\begin{array}{l}\text { Intense agriculture, early } \\
\text { season }\end{array}$ & Lower & Higher & Lower & No association & No association \\
\hline $\begin{array}{l}\text { Intense agriculture, late } \\
\text { season }\end{array}$ & Higher & Higher & Lower & Larger & No association \\
\hline $\begin{array}{l}\text { More small rural settlements } \\
\text { and hedges }\end{array}$ & No association & No association & No association & No association & Higher \\
\hline Smaller field parcels & Higher & No association & No association & No association & No association \\
\hline \multicolumn{6}{|c|}{ Disturbance factors around nest boxes } \\
\hline Short distance to house & No association & Higher & No association & No association & No association \\
\hline Livestock present & Lower & No association & Lower & No association & No association \\
\hline
\end{tabular}

\section{Effects of landscape characteristics on glucocorticoids, growth, and breeding performance}

Baseline corticosterone concentrations in barn owl nestlings varied along the season and with landscape characteristics around the breeding site. Early in the breeding season, when prey abundance is low (Aschwanden et al. 2007) but prey accessibility high, baseline corticosterone levels of nestlings were weakly negatively correlated with the intensity of the agricultural land use surrounding the breeding site. Late in the breeding season, when prey abundance is generally high but prey less accessible due to a dense and high vegetation cover (Aschwanden et al. 2005, 2007), we found a positive correlation between baseline corticosterone levels and the intensity of agricultural land use. This pattern most likely represents food availability for the nestlings and corroborates patterns found in other species, with baseline corticosterone levels increasing when food availability becomes scarce (Kitaysky et al. 2007, 2010) or the habitat becomes suboptimal (Bonier et al. 2007). Further, the negative correlation of relative body mass with baseline corticosterone (Table 2) also indicates that baseline corticosterone increases when the energy requirements of the nestlings are no longer satisfied. One function of corticosterone is to slow down growth (Hull et al. 2007; Müller et al. 2009) and to mobilise stored energy via gluconeogenesis (Wingfield et al. 1998) and baseline corticosterone often negatively correlates with body mass (Wingfield et al. 1994; Schoech et al. 1997). An explanation of the weak negative correlation of agricultural intensity and baseline levels early in the breeding season might be that a large proportion of the agriculture area is used for winter wheat 
which already accommodates a fair number of voles early in the breeding season (Arlettaz et al. 2010). With the available data we cannot distinguish between the direct effect of habitat quality (baseline levels increase when habitat quality decreases) and the indirect effect via the quality of the parents (low-quality territories might be occupied by lowquality parents).

Nestling body mass was generally lower late in the season than early and was lower in more intensively cultivated areas, which is an indication that food availability for nestlings in these areas may have been lower. The difference in body mass between habitat types might even affect post-fledging survival, as has been shown in other species (e.g. Perrins and McCleery 2001). The seasonal effect on nestling body mass helps to explain why some barn owls start breeding as early as spring conditions allow, even if this means that the birds lay smaller clutches [in contrast to most other bird species, clutch size increases along the season in barn owls (Frey et al. 2011)]. Vole and mice populations also increase along the season, but their accessibility or detectability decreases with vegetation cover (Arlettaz et al. 2010). For owls and other birds of prey it has been shown that vegetation structure is more important than small mammal abundance for the selection of hunting areas (Bechard 1982; Aschwanden et al. 2005; Arlettaz et al. 2010). Overall, our findings suggest that characteristics of man-made habitats influence both baseline corticosterone and growth.

We also found a strong correlation between the corticosterone response to an acute stressor and habitat characteristics. Nestlings reared in more intensively cultivated areas were more reactive to a new stressor, i.e. responded with a stronger release of corticosterone. Our results support findings of several studies showing that habitat condition and low food availability increase the reactivity of the HPA axis (Kitaysky et al. 2007; Romero and Wikelski 2010; Kitaysky et al. 2010). The increased reactivity of the HPA axis in more intensively cultivated areas did not depend on the season, while the effect on baseline corticosterone did. This suggests that baseline corticosterone and the acute glucocorticoid response to a stressor respond to different environmental cues or to different time scales. Baseline corticosterone seems to be more sensitive to the amount of food brought to the nest and hence to short-term conditions, while the acute corticosterone response appears to be correlated with the overall intensification of the area (including anthropogenic disturbance which occurs more frequently in intensively cultivated areas) and hence to longer-term conditions.

Clutch size, but not number of fledglings, increased along the season and this effect was more pronounced in more intensively cultivated areas. Also number of fledglings was strongly related to landscape characteristics. In areas with more anthropogenic landscape structures more nestlings survived until fledging than in areas with less structural diversity. In areas with more anthropogenic structures, and hence more different habitat types, overall food availability is probably more stable over the season and fledgling success is increased. A recent analysis of a larger data set (23 years) from the same population could not detect a significant correlation between landscape characteristics and clutch size or number of fledglings (Frey et al. 2011). This contradictory result may be explained by the fact that the change in landscape characteristics over the 23 years may not have been captured by this latter study and, therefore, might have caused substantial noise preventing the detection of correlations between current habitat characteristics and previous breeding performance. The present study only considered 5 years around the time point when the data on landscape characteristics were collected and might therefore have a better accuracy in describing them.

\section{Effects of human activities around breeding sites on glucocorticoids, growth, and breeding performance}

Our two disturbance parameters (livestock present around barns with nest boxes and distance to the next inhabited house) stand for increased frequency and duration of presence of farmers at the breeding site. We found that nestlings growing up at sites where livestock were present had lower baseline corticosterone levels than nestlings at sites without livestock. Further, the acute corticosterone response to handling stress of nestlings was negatively related to the distance of the nest box to the next inhabited house. Frequent anthropogenic disturbance can cause chronic stress (e.g. Fowler 1999; Müllner et al. 2004; Walker et al. 2005) and that chronic stress can decrease baseline corticosterone as shown in previous studies in the wild and in captivity (Rich and Romero 2005; Cyr et al. 2007; Cyr and Romero 2007) and might be a sign of desensitisation of the HPA axis to a certain chronic stressor (Cyr and Romero 2009). The increased acute corticosterone response of nestlings living close to humans shows, on the other hand, that these nestlings are not habituated to anthropogenic disturbance (Cyr and Romero 2009). The latter finding is in line with results by Müllner et al. (2004) in the hoatzin (Opisthocomus hoazin). Even when parents choose to breed in a site with increased anthropogenic disturbance, and probably are habituated to it, nestlings may nevertheless be susceptible to anthropogenic disturbance which negatively affects their body mass and eventually survival. Whether an anthropogenic disturbance increases or decreases the HPA responsiveness depends strongly on the strength of the disturbance and on the life cycle stage of the animal [e.g. adults, nestlings, or older offspring may differ in how they 
perceive anthropogenic disturbance; (Romero and Wikelski 2002; Walker et al. 2005; Dickens and Romero 2013)]. Frequent anthropogenic disturbance around the breeding sites can also change female brooding behaviour. Personal observations suggest that if we visit nest boxes frequently during early brooding, females start to sleep outside the nest boxes sooner and hence can no longer thermoregulate and feed prey remains to the young nestlings during the day. It is also known from mammalian studies that maternal separation at early age can increase the acute corticosterone response later in life (reviewed in Romero 2004). Unfortunately, we do not have any information regarding when females started sleeping outside the nest boxes.

Whether livestock were present around the breeding site had also a strong effect on nestling body mass. Nestlings located in sites with livestock had significantly lower body mass than in sites without livestock (Table 4). That we could not detect any effect of the variable livestock present on the acute corticosterone response may be due to the more predictable occurrence of the farmers on a regular feeding scheme for their animals. Nestlings may get used to the presence of the farmers in the buildings and no longer respond with corticosterone secretion. However, because nestling barn owls eat the prey remains from the night during daylight hours (Roulin 2004b), they nevertheless might have been disturbed in their feeding behaviour. Also we cannot exclude the possibility that sites with livestock may be of poorer quality (fewer voles) than sites without livestock.

Variation in breeding performance, on the other hand, could not be explained by the anthropogenic disturbance measurements. For adult barn owls the landscape characteristics seem to be more relevant for breeding success than anthropogenic disturbance. The changes in the HPA reactivity and the effects on nestling body mass could, in the end, lead to reduced survival of nestlings and hence reduced reproductive success for the parents. However, it still has to be shown whether a more reactive HPA axis and/or lower body mass during development have fitness consequences for the barn owls beyond fledging.

\section{Conclusion}

Understanding the mechanism by which human activities affect reproduction and other fitness-related traits is crucial to mitigating the conflicts between human activities and wild animal populations. In the present study we showed that in nestlings of a synanthropic species the HPA axis (represented by baseline concentrations of glucocorticoids and the concentration attained by a standardized stressor), growth of the nestlings, and breeding performance are affected by landscape characteristics and anthropogenic activity around the breeding site. Small-scale anthropogenic activity and large-scale landscape characteristics affected baseline corticosterone concentration, HPA axis reactivity and nestling body mass. Whether baseline corticosterone concentration and HPA reactivity correlate with fitness measures is still under debate and results are contradictory (e.g. Breuner et al. 2008; Bonier et al. 2009a; Angelier et al. 2010). However, our study indicates that landscape characteristics could also explain one measure of breeding performance, namely the number of fledglings a breeding couple could raise. Overall, anthropogenic disturbance seems to affect offspring quality rather than quantity; whereas agricultural practice affects both offspring number and quality.

Our study clearly showed that even in a synanthropic species, which largely depends on human buildings for breeding, anthropogenic activity affects nestlings. We therefore recommend ornithologists to install nest boxes at sites with the least possible human activity.

Author contribution statement B. A., A. R. and L. J. conceived and designed the experiments. B. A. and P. B. performed the experiments. B. A. and P. B. analysed the data. B. A., A. R. and L. J. wrote the manuscript.

Acknowledgments We warmly thank all the field assistants who helped during the long field days and nights from 2004 to 2010. We thank C. Frey and C. Sonnay for collecting and preparing the data on habitat characteristics, and F. Korner-Nievergelt and G. Pasinelli for discussing model selection and averaging. S. Jenni-Eiermann, Z. Tablado, Y. Bötsch and Hannu Pöysä and two anonymous reviewers gave valuables comments on an earlier draft. The Swiss National Science Foundation supported the study financially (no. 31003A-127057 to L. J., no. 31003A-120517 to A. R.).

\section{References}

Almasi B, Jenni L, Jenni-Eiermann S, Roulin A (2010) Regulation of stress response is heritable and functionally linked to melaninbased coloration. J Evol Biol 23:987-996

Anderson DR, Burnham KP, Thompson WL (2000) Null hypothesis testing: problems, prevalence, and an alternative. J Wildl Manage 64:912-923

Angelier F, Wingfield JC, Weimerskirch H, Chastel O (2010) Hormonal correlates of individual quality in a long-lived bird: a test of the 'corticosterone-fitness hypothesis'. Biol Lett 6:846-849

Arlettaz R, Krähenbühl M, Almasi B, Roulin A, Schaub M (2010) Wildflower areas within revitalized agricultural matrices boost small mammal populations but not breeding barn owls. J Ornithol 151:553-564

Aschwanden J, Birrer S, Jenni L (2005) Are ecological compensation areas attractive hunting sites for common kestrels (Falco tinnunculus) and long-eared owls (Asio otus)? J Ornithol 146:279-286

Aschwanden J, Holzgang O, Jenni L (2007) Importance of ecological compensation areas for small mammals in intensively farmed areas. Wildl Biol 13:150-158

Bates D, Maechler M, Bolker B (2012) lme4: linear mixed-effects models using S4 classes. R package version 0.999999-0. http:// cran.r-project.org/web/packages/lme4/index.html 
Bauer CM, Skaff NK, Bernard AB, Trevino JM, Ho JM, Romero LM, Ebensperger LA, Hayes LD (2013) Habitat type influences endocrine stress response in the degu (Octodon degus). Gen Comp Endocrinol 186:136-144

Bechard MJ (1982) Effect of vegetative cover on foraging site selection by Swainsons hawk. Condor 84:153-159

Bernaards C, Jennrich R (2012) GPArotation: GPA factor rotation. R package version 2012.3-1. http://cran.r-project.org/web/ packages/GPArotation

Bonier F, Martin PR, Sheldon KS, Jensen JP, Foltz SL, Wingfield JC (2007) Sex-specific consequences of life in the city. Behav Ecol 18:121-129

Bonier F, Martin PR, Moore IT, Wingfield JC (2009a) Do baseline glucocorticoids predict fitness? Trends Ecol Evol 24:634-642

Bonier F, Moore IT, Martin PR, Robertson RJ (2009b) The relationship between fitness and baseline glucocorticoids in a passerine bird. Gen Comp Endocrinol 163:208-213

Breuner CW, Patterson SH, Hahn TP (2008) In search of relationships between the acute adrenocortical response and fitness. Gen Comp Endocrinol 157:288-295

Bundesamt für Landwirtschaft (BLW) (2014) Agrarbericht 2014

Burnham KP, Anderson DR (2002) Model selection and multimodel inference: a practical information-theoretic approach. Springer, Berlin

Chavez-Zichinelli CA, MacGregor-Fors I, Quesada J, Rohana PT, Romano MC, Valdez R, Schondube JE (2013) How stressed are birds in an urbanizing landscape? Relationships between the physiology of birds and three levels of habitat alteration. Condor 115:84-92

Cockrem JF, Silverin B (2002) Variation within and between birds in corticosterone responses of great tits (Parus major). Gen Comp Endocrinol 125:197-206

Cyr NE, Romero L (2007) Chronic stress in free-living European starlings reduces corticosterone concentrations and reproductive success. Gen Comp Endocrinol 151:82-89

Cyr NE, Romero LM (2009) Identifying hormonal habituation in field studies of stress. Gen Comp Endocrinol 161:295-303

Cyr NE, Earle K, Tam C, Romero L (2007) The effect of chronic psychological stress on corticosterone, plasma metabolites, and immune responsiveness in European starlings. Gen Comp Endocrinol 154:59-66

Dickens MJ, Romero LM (2013) A consensus endocrine profile for chronically stressed wild animals does not exist. Gen Comp Endocrinol 191:177-189

Donald PF, Green RE, Heath MF (2001) Agricultural intensification and the collapse of Europe's farmland bird populations. Proc R Soc Lond Ser B Biol Scie 268:25-29

Fowler GS (1999) Behavioral and hormonal responses of Magellanic penguins (Spheniscus magellanicus) to tourism and nest site visitation. Biol Conserv 90:143-149

Frey C, Sonnay C, Dreiss AN, Roulin A (2011) Habitat, breeding performance, diet and individual age in Swiss barn owls (Tyto alba). J Ornithol 152:279-290

Hollander FA, Van Dyck H, Martin GS, Titeux N (2011) Maladaptive habitat selection of a migratory passerine bird in a human-modified landscape. Plos One 6:e25703

Hull KL, Cockrem JF, Bridges JP, Candy EJ, Davidson CM (2007) Effects of corticosterone treatment on growth, development, and the corticosterone response to handling in young Japanese quail. Comp Biochem Physiol A Mol Integr Physiol 148:531-543

Johnston RF (2001) Synanthropic birds of North America. In: Marzluff JM, Bowman R, Donnelly RE (eds) Avian ecology and conservation in an urbanizing world. Kluwer, Boston, pp 49-67

Kitaysky AS, Piatt JF, Wingfield JC (2007) Stress hormones link food availability and population processes in seabirds. Mar Ecol Progr Ser 352:245-258
Kitaysky AS, Piatt JF, Hatch SA, Kitaiskaia EV, Benowitz-Fredericks ZM, Shultz MT, Wingfield JC (2010) Food availability and population processes: severity of nutritional stress during reproduction predicts survival of long-lived seabirds. Funct Ecol 24:625-637

Konstantinov VM (1996) Anthropogenic transformations of bird communities in the forest zone of the Russian plain. Acta Ornithol (Warsaw) 31:53-58

Lynn SE, Prince LE, Phillips MM (2010) A single exposure to an acute stressor has lasting consequences for the hypothalamopituitary-adrenal response to stress in free-living birds. Gen Comp Endocrinol 165:337-344

Madliger CL, Love OP (2014) The need for a predictive, contextdependent approach to the application of stress hormones in conservation. Conserv Biol 28:283-287

Marzluff JM (2001) Worldwide urbanization and its effects on birds. In: Marzluff JM, Bowman R, Donnelly RE (eds) Avian ecology and conservation in an urbanizing world. Kluwer, Boston, pp 19-49

Mebs T, Scherzinger W (2000) Die Eulen Europas. Biologie, Kennzeichen, Bestände. Franckh-Kosmos, Stuttgart

Müller C, Jenni-Eiermann S, Blondel J, Perret P, Caro SP, Lambrechts M, Jenni L (2006) Effect of human presence and handling on circulating corticosterone levels in breeding blue tits (Parus caeruleus). Gen Comp Endocrinol 148:163-171

Müller C, Jenni-Eiermann S, Jenni L (2009) Effects of a short period of elevated circulating corticosterone on postnatal growth in free-living Eurasian kestrels Falco tinnunculus. J Exp Biol 212:1405-1412

Müllner A, Linsenmair KE, Wikelski M (2004) Exposure to ecotourism reduces survival and affects stress response in hoatzin chicks (Opisthocomus hoazin). Biol Conserv 118:549-558

Munro CJ, Lasley BL (1988) Non-radiometric methods for immunoassay of steroid hormones. In: Albertson BD, Haseltine FP (eds) Non-radiometric assays: technology and application in polypeptide and steroid hormone detection. Liss, New York, pp 289-329

Munro CJ, Stabenfeldt G (1984) Development of a microtitre plate enzyme immunoassay for the determination of progesterone. $\mathrm{J}$ Endocrinol 101:41-49

Partecke J, Schwabl I, Gwinner E (2006) Stress and the city: urbanization and its effects on the stress physiology in European blackbirds. Ecology 87:1945-1952

Perrins CM, McCleery RH (2001) The effect of fledging mass on the lives of great tits Parus major. Ardea 89:135-142

R Development Core Team (2012) R: A language and environment for statistical computing. R Development Core Team, R Foundation for Statistical Computing, Vienna

Revelle W (2012) Psych: procedures for psychological, psychometric, and personality research. $\mathrm{R}$ package version 1.2 .8 . http://cran.rproject.org/web/packages/psych

Rich EL, Romero LM (2005) Exposure to chronic stress downregulates corticosterone responses to acute stressors. Am J Physiol 288:1628-1636

Romero LM (2004) Physiological stress in ecology: lessons from biomedical research. Trends Ecol Evol 19:249-255

Romero LM, Reed JM (2005) Collecting baseline corticosterone samples in the field: is under 3 min good enough? Comp Biochem Physiol 140:73-79

Romero LM, Wikelski M (2002) Exposure to tourism reduces stressinduced corticosterone levels in Galapagos marine iguanas. Biol Conserv 108:371-374

Romero LM, Wikelski M (2010) Stress physiology as a predictor of survival in Galapagos marine iguanas. Proc R Soc B Biol Scie 277:3157-3162

Roulin A (2002) Short- and long-term fitness correlates of rearing conditions in barn owls Tyto alba. Ardea 90:259-267 
Roulin A (2004a) Covariation between plumage colour polymorphism and diet in the barn owl Tyto alba. Ibis 146:509-517

Roulin A (2004b) The function of food stores in bird nests: observations and experiments in the barn owl Tyto alba. Ardea 92:69-78

Roulin A, Almasi B, Jenni L (2010) Temporal variation in glucocorticoid levels during the resting phase is associated in opposite way with maternal and paternal melanic coloration. J Evol Biol 23:2046-2053

Sapolsky RM, Romero LM, Munck AU (2000) How do glucocorticoids influence stress responses? Integrating permissive, suppressive, stimulatory, and preparative actions. Endocrinol Rev 21:55-89

Schoech SJ, Mumme RL, Wingfield JC (1997) Corticosterone, reproductive status, and body mass in a cooperative breeder, the Florida scrub-jay (Aphelocoma coerulescens). Physiol Zool 70:68-73

Strasser EH, Heath JA (2013) Reproductive failure of a human-tolerant species, the American kestrel, is associated with stress and human disturbance. J Appl Ecol 50:912-919

Taylor IR (1993) Age and sex determination of barn owls Tyto alba alba. Ringing Migr 14:94-102

Thiel D, Jenni-Eiermann S, Braunisch V, Palme R, Jenni L (2008) Ski tourism affects habitat use and evokes a physiological stress response in capercaillie Tetrao urogallus: a new methodological approach. J Appl Ecol 45:845-853

Walker BG, Boersma PD, Wingfield JC (2005) Physiological and behavioral differences in Magellanic penguin chicks in undisturbed and tourist-visited locations of a colony. Conserv Biol 19:1571-1577

Wikelski M, Cooke SJ (2006) Conservation physiology. Trends Ecol Evol 21:38-46

Wingfield JC, Deviche P, Sharbaugh S, Astheimer LB, Holberton R, Suydam R, Hunt K (1994) Seasonal-changes of the adrenocortical responses to rtress in redpolls, Acanthis flammea, in Alaska. $\mathrm{J}$ Exp Zool 270:372-380

Wingfield JC, Maney DL, Breuner C, Jacobs JD, Lynn S, Ramenofsky M, Richardson RD (1998) Ecological bases of hormonebehavior interactions: the "emergency life history stage". Am Zool 38:191-206

Zhang SP, Lei FM, Liu SL, Li DM, Chen C, Wang PZ (2011) Variation in baseline corticosterone levels of tree sparrow (Passer montanus) populations along an urban gradient in Beijing, China. J Ornithol 152:801-806 